\title{
Nasionalisme Buruh Versus Kolonialisme: Suatu Kajian Tentang Gerakan Buruh di Semarang pada Awal Abad XX
}

\author{
Dewi Yuliati ${ }^{*)}$ \\ ${ }^{1}$ Program Studi Sejarah, Fakultas Ilmu Budaya, Universitas Diponegoro, Jl. Prof. Soedarto, SH, Kampus \\ Undip Tembalang, Semarang, Indonesia \\ ${ }^{*}$ Korespondesi: dewi_yulliati@yahoo.co.id
}

\begin{abstract}
[Workers Nationalism Versus Colonialism: A Study on Workers Movement in Semarang in The Beginning of the $2^{\text {th }}$ Centuries]. The state and the workers have close relationship, because the state is a political unity between the folks (includes the workers) and the government as the states' administrator. In the context of industrial relationship, there often take place interest differences between the state and the workers, and this condition can arise conflict between these two parties. Generally, the workers are judged as the marginal party who struggle only for the economical reasons, without any thinking of political stability. This research shows that this point of view is not exactly true, because the workers really dare to search justice and prosperity for the indigenous people who are the part of the citizens of the state.Based on this research can be concluded that the basic factors of the workers movement were not only economic interest, but also the spirit of anticolonial nationalism, which included the willingness to get liberty, juctice, and to show national dignity.
\end{abstract}

Keywords: worker nationalism; worker movement; anticolonial nationalism

\begin{abstract}
Abstrak
Negara dan buruh berhubungan erat, karena negara adalah suatu kesatuan politik antara rakyat (termasuk buruh) dan pemerintah sebagai administrator (pengurus) negara. Dalam konteks hubungan industrial, sering terjadi perbedaan kepentingan antara negara dan buruh, dan kondisi ini dapat menimbulkan konflik di antara dua pihak tersebut. Secara umum, buruh sering dianggap sebagai pihak marjinal yang hanya berjuang untuk alasan ekonomi, tanpa mempertimbangkan stabilitas politik. Akan tetapi, penelitian ini menemukan fakta bahwa pandangan tersebut tidak benar sepenuhnya, karena kenyataannya kaum buruh berani menuntut keadilan dan kesejahteraan untuk rakyat bumiputera yang menjadi bagian dari warga negara. Dari penelitian ini dapat disimpulkan bahwa factor-faktor yang mendasari gerakan buruh tidak hanya kepentingan ekonomi, tetapi juga suatu semangat nasionalisme antikolonial, yang mencakup keinginan untuk merdeka, memperoleh keadilan, dan menunjukkan harga diiri bangsa.
\end{abstract}

Kata kunci: nasionalisme buruh; gerakan buruh; nasionalisme antikolonial

\section{A. Pendahuluan}

Dalam penelitian ini buruh diartikan sebagai orang yang bekerja pada perusahaan baik swasta maupun pemerintah untuk memperoleh gaji atau upah. Secara harafiah buruh, sebuah kata yang berasal dari bahasa Jawa, adalah orang yang bekerja dengan tujuan memperoleh bayaran berupa uang.

Dalam percakapan sehari-hari buruh dapat dibedakan atas buruh kantor (karyawan yang bekerja di kantor), buruh kasar/kuli/unskilled labour (karyawan yang bekerja dengan tenaga badan), dan buruh trampil (karyawan yang mempunyai ketrampilan tertentu seperti: tukang kayu, tukang jahit, tukang batu, juru ketik dan sebagainya) (Ensiklopedi Indonesia, 1980: 557). Buruh dapat dibedakan juga atas dasar tingkat ketrampilannya dalam suatu perusahaan, yaitu buruh trampil, buruh semitrampil, dan buruh tidak trampil. 
Pada umumnya tingkat ketrampilan buruh tersebut menentukan sistem pengupahan. Buruh trampil dapat bekerja secara permanen, diberi upah secara bulanan, mendapat cuti tahunan, tunjangan sakit, mendapat upah lebih tinggi daripada buruh dengan tingkat ketrampilan lebih rendah, pensiun, bonus tahunan, dan uang makan. Buruh semitrampil menerima upah yang dihitung sesuai dengan jumlah hari kerja, dan menerima jumlah tunjangan lebih sedikit daripada tunjangan untuk buruh trampil. Biasanya buruh tidak trampil hanya dibayar untuk hari-hari ia bekerja (John Ingleson,1986: 25).

Dalam hubungan industrial, sering terjadi perselisihan industrial yang berbentuk perselisihan kepentingan ( conflict of interest). Pada awal abad ke-20, conflict of interest dalam hubungan industrial itu tampak secara nyata dalam khasanah pergerakan buruh (labour movement), yang sering dipandang oleh negara kolonial bahwa kaum buruh berjuang hanya untuk kepentingan ekonomi, dan sering "ditunggangi" oleh kepentingan politik. Berdasarkan permasalahan tersebut, tujuan pelaksanaan kajian ini adalah untuk menyajikan analisis tentang gerakan buruh di Semarang pada awal abad XX beserta faktor-faktor penggeraknya dengan panduan pertanyaan penelitian sebagai berikut.

(1). Mengapa buruh bergerak?, (2). Bagaimana proses pergerakan buruh? (3) Bagaimana negara kolonial bersikap dan bertindak dalam mengatasi pergerakan buruh?, (3). Bagaimana hasil pergerakan buruh itu?.

\section{B. Landasan Teori}

Gerakan buruh pada masa kolonial Belanda di Indonesia sering dipandang sebagai gerakan yang didorong oleh kepentingan ekonomi semata, padahal ternyata, kepentingan ekonomi itu bukanlah satu-satunya faktor penggerak. Dari penelitian ditemukan bahwa ada faktor penggerak gerakan buruh yang lebih kuat, yaitu nasionalisme antikolonial. Nasionalisme dapat dipahami dari sudut pandang antropologi dan politik. Dalam dimensi antropologi, nasionalisme dipandang sebagai sistem budaya yang mencakup kesetiaan, komitmen, emosi, perasaan kepada bangsa dan negara, dan rasa memiliki bangsa dan negara itu. Dalam dimensi ini, Benedict Anderson mengatakan bahwa nation (bangsa) adalah suatu komunitas politik yang terbatas dan beradaulat yang dibayangkan (imagined communities). Komunitas politik itu dikatakan sebagai imagined communities sebab suatu komunitas tidak mungkin mengenal seluruh warganya, tidak mungkin saling bertemu, atau saling mendengar. Akan tetapi, mereka memiliki gambaran atau bayangan yang sama tentang komunitas mereka. Suatu bangsa dapat terbentuk, jika sejumlah warga dalam suatu komunitas mau menetapkan diri sebagai suatu bangsa yang mereka angankan atau bayangkan (Benedict Anderson, 1983: 15). Karena komitmen dan keinginan untuk mengikatkan diri dalam komunitas bangsa ini, dapat muncul kesetiaan yang tinggi pada nation state (negara kebangsaan). Bahkan, banyak warga suatu negara bangsa (nation state) rela mengorbankan jiwa-raga untuk membela bangsa dan negara mereka. Senada dengan Benedict Anderson, Ernest Renan mengatakan bahwa unsur utama dalam pembentukan suatu bangsa adalah le desir de' etre ensemble (keinginan untuk bersatu) (Taufik Abdullah, 2001: 49). 
Pada awal abad ke-20 pemahaman rakyat bumiputera Indonesia tentang nasionalisme sebagai konsep ideologis masih sangat "samar-samar" bagaikan "alam fajar", mereka belum memiliki tujuan yang jelas, dan apa yang harus mereka lakukan untuk negeri dan bangsanya. Salah satu contoh adalah pernyataan Abdoel Moeis, seorang tokoh Sarekat Islam, yang mengartikan nasionalisme sebagai perasaan cinta kepada bangsa dan tanah air, yang diungkapkannya pada harian Sinar Djawa, 25 Oktober 1917 sebagai berikut:

Kalaoe kita mengingat akan nasib boeroeknja tanah air dan bangsa kita, jang beratoes tahoen selaloe berada dalam koengkoengan orang lain sadja, maka berdebarlah dada, timboellah soeatoe perasaan jang menggojang segala oerat saraf kita, perasaan kasihan kepada bangsa dan tanah air itoe (Sinar Djawa, 25 Oktober 1917).

Dalam dimensi politik, nasionalisme merupakan ideologi yang meyakini bahwa kesetiaan tertinggi individu harus diserahkan kepada negara bangsa, yaitu suatu negara yang mampu menjamin seluruh warga bangsanya untuk mendapatkan hak dan kewajiban yang sama serta mampu membuat warga bangsanya mau mengikatkan dirinya pada negara itu (Hans Kohn, 1984: 75). Soekarno, presiden pertama Indonesia, mengatakan bahwa bangsa adalah sebuah konstruksi yang dihasilkan oleh sebuah visi yang diperjuangkan, Dalam pengertian politik ini, prinsip-prinsip utama dalam nasionalisme adalah kemerdekaan, kesatuan, keadilan, dan identitas national, yang menjadi orientasi kehidupan kolektif suatu kelompok untuk mencapai tujuan politik, yaitu negara bangsa. Sebagai doktrin politik, nasionalisme merupakan basis serta pembenaran ideologis bagi setiap bangsa di dunia untuk mengorganisasi diri dalam entitas-entitas yang bebas atau otonom, dan entitas itu berbentuk negara bangsa yang merdeka (Michael A. Riff, 2001: 194.).

Secara budaya, nasionalisme itu merupakan gejala historis yang bersifat universal, yang muncul di semua ruang bangsa. Bagaimana gejala awal pertumbuhan nasionalisme di Indonesia, hanya dapat dijawab melalui pemahaman terhadap sejarah kemunculan kesadaran berbangsa.

Untuk menjelaskan awal kemunculan nasionalisme Indonesia itu, diperlukan pemahaman terhadap situasi kolonial pada akhir abad ke-19 dan awal abad ke-20. Pada saat itu ikatan tradisi dan feodalisme serta diskriminasi masih sangat membatasi aktivitas dan ruang gerak bangsa bumiputera di Hindia Belanda (Indonesia), padahal di sisi lain sudah lahir golongan terpelajar bumiputera yang telah memiliki kesadaran untuk membebaskan diri dari belenggu tradisi feodalisme dan mempunyai kesadaran untuk mengadakan gerakan perlawanan terhadap kolonialisme.

\section{Metode Penelitian}

Penelitian ini merupakan penelitian sejarah. Dengan demikian metode yang dipergunakan adalah metode historis yaitu mencari, menemukan, dan menguji sumber-sumber sehingga dapat diperoleh fakta sejarah yang otentik dan kredibel. Dalam penulisan dilakukan penyusunan fakta-fakta yang 
masih fragmentaris itu ke dalam suatu sintesa yang sistimatis, utuh, dan komunikatif. Untuk mencapai hasil penulisan sejarah yang demikian, diperlukan suatu penelitian yang tidak saja berangkat dari pertanyaan-pertanyaan pokok tentang "apa, siapa, di mana, dan kapan", tetapi juga berdasar pada pertanyaan "bagaimana", "mengapa serta apa jadinya". Jawaban terhadap pertanyaanpertanyaan pokok adalah fakta sejarah serta unsur-unsur yang turut membentuk peristiwa di tempat dan pada waktu tertentu. Jawaban terhadap pertanyaan "bagaimana" merupakan rekonstruksi peristiwa masa lampau dengan cara menyintesiskan semua unsur itu dalam suatu deskripsi yang disebut sejarah. Jawaban terhadap pertanyaan "mengapa dan apa jadinya" akan menerangkan hubungan kausalitas.

Sumber-sumber diperoleh dari berbagai perpustakaan yaitu Perpustakaan Monumen Pers Surakarta, Perpustakaan Nasional dan Arsip Nasional Jakarta. Sumber -sumber tertulis yang diteliti adalah dokumen pemerintah, berbagai surat kabar di Jawa pada masa kolonial Belanda, dan tulisan-tulisan sejaman yang berkait dengan masalah-masalah perburuhan.

\section{Hasil dan Pembahasan}

\section{Latar Belakang Menguatnya Nasionalisme Buruh}

Antara tahun 1910-1912 di Hindia Belanda terjadi kenaikan harga barang-barang kebutuhan sehari-hari. Harga beras naik 30\%, gula 9\%, kentang 25\%, kain katun 10\%, minyak kelapa 6\%, dan bambu 90\%. Kenaikan harga barang-barang ini tidak disertai dengan kenaikan upah (De Locomotief. 18 Maret 1913). Nilai upah buruh bumiputera yang sangat minimal (tidak lebih dari f. 1,- per hari) semakin tidak dapat untuk menjangkau kebutuhan pokok.

Memasuki Perang Dunia I, kehidupan ekonomi buruh semakin merosot. Ketika itu inflasi meningkat dan pengusaha Eropa mengeruk keuntungan besar karena kenaikan permintaan ekspor hasil-hasil perkebunan dari Indonesia. Sebaliknya nilai upah semakin menurun karena kenaikan harga barang-barang impor dan dengan sendirinya juga harga barang-barang dalam negeri, sedangkan upah tidak dinaikkan. Kondisi ini menjadi bagian latar belakang maraknya aksi mogok kaum buruh pada akhir dekade ke-2 sampai pertengahan dekade ke-3 abad ke-20.

Setelah Perang Dunia I berakhir, rakyat Jawa hidup dengan tingkat pendapatan yang sangat minimal. Yeekes menerangkan dalam De Opbouw (tahun 1923) bahwa pendapatan rata-rata per tahun buruh bumiputera adalah f. 196,-. Dari jumlah pendapatan itu masih harus ada yang dikeluarkan untuk membayar pajak, sehingga pendapatan rata-rata per bulan tinggal sekitar f. 13,-. (Tan Malaka, 2000: 52.).

Seorang tokoh pergerakan buruh, Tan Malaka, sangat meratapi kondisi kemiskinan buruh bumiputera itu. Ia mengungkapkan bahwa orang Jawa tinggal di pondok-pondok rombeng atau tidak bertempattinggal sama sekali, kelaparan, berpakaian compang-camping, dan kesehatannya tidak terawat. Jika terjadi wabah malaria, kolera, cacing tambang, dan sampar, "hanya" ratusan ribu orang mati karena mereka tidak memiliki ketahanan tubuh untuk menghadapi serangan berbagai penyakit (Tan Malaka, 2000: 52.). "Suatu keuletan 
yang patut dipuji" adalah ungkapan Tan Malaka untuk menggambarkan ketabahan dan kesabaran buruh di Jawa dalam menghadapi berbagai kesulitan dan kekurangan itu.

Kesulitan ekonomi pada masa Perang Dunia I itu tercermin antara lain pada keluhan Perhimpoenan Roro Jitno (perhimpunan pekerja partikulir) tentang dampak perang itu bagi kaum buruh.

Dari timboelnja perang itoe beberapa koeli di pabean soedah poelang ke roemahnja karena soedah tidak ada pekerdjaan jang moesti diangkatnja boeat mendapetken oeang pembeli isi peroet. Ada djoega mandor-mandor dan pegawei di toko atau maatschappij soedah dilepas dengan pesangon, tetapi tiada semoea toko berlakoe begitoe moerah (Sinar Djawa, 27 Februari 1915).

Karena desakan kesulitan ekonomi itu, Perhimpoenan Roro Jitno membuat surat terbuka yang ditujukan kepada Centraal Comite Kesengsaraan di Batavia untuk meminta derma bagi orang-orang yang terkena pelepepasan hubungan kerja itu.

Jang taroh tanda tangan di bawah ini voorlopig hoofdbestuur dari Perhimpoenan Roro Jitno atoer beri taoe bahwa pada waktoe jang amat soekar ini, jaitoe waktoe di Europa timboel perang besar, boekan di Europa sadja jang pendoedoeknja dapet sengsara, poen di Hindia Nederland begitoe djoega. Perkataan sengsara ini artinja boekan orang jang terserang bahaja perang, tetapi sebab berhenti dari pekerdjaannja. Moelai boelan Augustus banjak mandoer berhenti dari pekerdjaannja, dan banjak toekang serta koeli tiada dapat pekerdjaan sebagaimana biasa. Lantaran itoe voorlopig hoofdbestuur Perhimpoenan Roro Jitno mohon dengan sangat dan dengan hormat soepaja derma goena kesengsaraan di Hindia Nederland itoe segera dibagikan kepada orang-orang jang dapet sengsara terseboet (Sinar Djawa, 27 Februari 1915.).

Selain kesulitan untuk mendapat pekerjaan dan pemutusan hubungan kerja, kesengsaraan kaum buruh bumiputera masih diperberat oleh kenaikan harga barang-barang kebutuhan pokok sebagai akibat perang. Kenaikan harga barang-barang dalam masa dan sesudah perang itu disebabkan oleh faktor-faktor sebagai berikut. Pertama, impor barang-barang kebutuhan pokok terhambat oleh ketiadaan kapal pengangkut, karena sejumlah besar kapal Belanda diperlukan oleh Inggris untuk kepentingan perang. Kedua, pada tahun 1917 Inggris melarang ekspor beras dari India dan Singapore ke Hindia Belanda. Dengan demikian persediaan bahan-bahan makanan menipis dan harga barang-barang kebutuhan naik. Periode pertengahan 1918 sampai 1920 merupakan masa kemerosotan ekonomi di Indonesia. Pada periode itu terjadi inflasi yang sangat tinggi. Semua harga barang kebutuhan hidup naik, sedangkan gaji atau upah tetap. Pada pertengahan Agustus 1918 harga bahan-bahan makanan, pakaian, dan barangbarang keperluan rumah tangga naik lebih dari 50\% (George D. Larson, 1987: 104).

Ketiga, ekstensifikasi perkebunan-perkebunan dengan memanfaatkan peranan lurah untuk memaksa petani agar mau menyewakan tanahnya kepada pengusaha perkebunan. Para lurah terdorong untuk memaksa petani agar menyewakan tanahnya pada perkebunan, karena mereka mendapat premi $\mathrm{f}$. 2,50,- untuk setiap bau (1 bau $\left.=7096 \mathrm{~m}^{2}\right)$ tanah petani yang disewakan (Sinar Hindia, 5 Mei 1918.). Dengan demikian, areal perkebunan semakin meluas, dan areal penanaman padi semakin menyempit. Implikasi ekstensifikasi lahan tanaman ekspor ini adalah kecenderungan peningkatan ekspor produkproduk pertanian (Theo Steven, 1979: 93).

Harga beras terus membubung tinggi. Pada Februari 1918 harga beras nomer satu mencapai f. 14 per pikul atau 22,7 sen per kg., dan beras nomer dua f. 13 per pikul ( 1 pikul = 61,76 kg.) atau $21 \mathrm{sen}$ per kg. (Liem Thian Joe, 1931: 237). Harga yang sudah sangat tinggi ini, pada tahun 1919 mengalami 
kenaikan lagi. Beras nomer satu berharga f. 16 per pikul, beras nomer dua f. 15 per pikul, dan beras nomer tiga f. 14 per pikul (Sinar Hindia, 14 Januari 1919). Demikian juga, harga gula mencapai f. 16 per pikul atau f. 0,26 per kg.(Liem Thian Joe, 1931: 234). Bagi kaum buruh bumiputera yang berpenghasilan hanya sekitar f. 0,50,- per hari, harga beras dan gula yang demikian tinggi tentu menjadi beban hidup yang sangat berat (Sinar Hindia, 20 Februari 1920).

Tan Malaka menggambarkan jutaan kaum pekerja atau buruh bumiputera pada waktu itu sebagai budak belian kolonial, yang sangat tertindas oleh upah yang hanya dapat mencukupi kebutuhan untuk tidak mati kelaparan. Buruh kereta api, trem, dan buruh-buruh lainnya mulai bekerja dengan gaji sekitar f. 15,- dan mencapai maksimum f. 30,- sampai f. 40,- per bulan ketika mereka sudah beruban (Tan Malaka, 2000: 49).

Gejala kemerosotan ekonomi ini tentu diiringi dengan penurunan tingkat kesehatan rakyat. Sebagai contoh, pada tahun 1917 penduduk Kota Semarang terlanda wabah pes yang berakibat kematian beratus-ratus orang. Di bawah ini dikemukakan data angka kematian penduduk di Semarang pada tahun 1917.

Tabel 1. Angka Kematian Penduduk Semarang per 1000 jiwa (tahun 1917)

\begin{tabular}{|l|c|c|}
\hline Nama Kampung & Triwulan Pertama & Triwulan Ke dua \\
\hline \hline Semarang Kulon & 48 & 67 \\
\hline \hline Semarang Kidul & 32 & 57 \\
\hline \hline Semarang Wetan & 59 & 72 \\
\hline \hline Semarang Tengah & 45 & 49 \\
\hline \hline Genuk & 24 & 64 \\
\hline \hline Pedurungan & 26 & 90 \\
\hline \hline Srondol & 13 & 23 \\
\hline \hline Mranggen & 26 & 151 \\
\hline \hline Kranggan & 24 & 115 \\
\hline \hline Gedongbatu & 20 & 98 \\
\hline
\end{tabular}

Sumber: Darsono, “Giftige Waarheidspijlen” dalam Sinar Hindia 18 Mei 1918.

Dalam menyikapi kenaikan harga beras itu, Sarekat Islam Semarang menggelar rapat umum pada tanggal 10 Februari 1918 di Stadstuin (alun-alun) Semarang yang dihadiri oleh pengurus-pengurus cabang dan 3000 anggota. Dalam rapat itu Sarekat Islam Semarang memutuskan untuk menyampaikan surat kepada gubernur jenderal yang berisi tuntutan penurunan harga beras (Sinar Djawa 12 Februari 1918). Namun demikian, tuntutan itu tak kunjung dipenuhi oleh pemerintah kolonial. Frustrasi yang diderita oleh kaum buruh karena tekanan ekonomi, politik, dan budaya dalam masyarakat kolonial itu memunculkan kesadaran bersama kaum buruh untuk memperjuangkan perbaikan nasib, yang terutama dilakukan dengan aksi mogok.

\section{Pemogokan Buruh Pegadaian: Ekspresi Harga Diri Bangsa}


Pada awal abad ke-20, di Semarang telah ada empat kantor pegadaian yaitu di Mlaten, Poncol, Depok, dan Karang Turi. Pada tanggal 21 Januari 1922, pegawai-pegawai bumiputera di kantor-kantor pegadaian itu melakukan pemogokan. Jika pada umumnya aksi pemogokan buruh didasari oleh kekecewaan terhadap kegagalan tuntutan perbaikan gaji dan syarat-syarat pekerjaan yang lain, pemogokan pegawai pegadaian itu dipicu oleh persoalan harga diri.

Sehari sebelum terjadi pemogokan, ada seorang pegawai pegadaian Karang Turi yang diperintah oleh beheerder (Kepala Pegadaian) untuk mengangkat barang-barang ke tempat pelelangan. Pegawai tersebut menolak, tetapi beheerder menetapkan bahwa barang-barang harus diangkat sendiri oleh pegawai itu. Kemudian perselisihan ini merupakan faktor pemicu pecahnya pemogokan di kantor-kantor pegadaian di kota Semarang (Liem Thian Joe, 1931: 258).

Kesadaran akan harga diri tampak semakin mengristal dalam "openbare protest vergadering pemogokan dalam doenia pegadean" pada tanggal 22 Januari 1922 di kantor Sarekat Islam Semarang di Kampung Gendong. Dalam rapat yang dihadiri oleh sekitar 5000 orang itu, Tan Malaka menunjukkan sikap orang Belanda yang sangat melecehkan orang bumiputera sebagai berikut.

Orang-orang Belanda jang datang di sini, meskipoen di sana mereka hanja djadi toekang menggosok sepatoe sadja, di sini djadi zinder sadja tidak soeka mengangkat barang sedikit sadja. Djika mengangkat barang jang berat sedikit minta pertoeloengannja djongos, baboe, koki. Begitoepoen njonjah-njonjah besarnja, anak-anaknja jang masih ketjil sadja djoega telah dididik panggil djongos, baboe, koki. Boleh djadi anaknja jang masih dalam kandoengan iboenja telah diadjarkan adat itoe (Sinar Hindia, 23 Januari 1922).

Penolakan pegawai pegadaian terhadap perintah atasannya itu bukanlah tanpa dasar. Pada tahun 1919 telah dikeluarkan peraturan bahwa pengangkatan barang-barang ke tempat pelelangan dapat dilakukan oleh tukang kebun (Sinar Hindia, 16 Januari 1922). Namun demikian, karena pemerintah memberlakukan penghematan belanja negara, banyak kuli yang bertugas mengangkat barang-barang lelangan dipecat, dan tugas mereka dibebankan kepada para pegawai administratif. Ketika beheerder (kepala pegadaian) mengharuskan seorang pegawai untuk mengangkat sendiri barang-barang itu ke tempat pelelangan, sangatlah wajar jika timbul penolakan.

Selain persoalan harga diri, tampaknya pemogokan pegawai pegadaian di Semarang juga didorong semangat solidaritas terhadap pegawai pegadaian Ngupasan Yogyakarta yang telah melancarkan pemogokan sejak tanggal 11 sampai 18 Januari 1922 dengan faktor pemicu yang sama, yaitu perintah beheerder terhadap seorang pegawai bumiputera untuk mengangkat sendiri barang-barang yang akan dilelang. Karena perintah tersebut ditolak oleh pegawai yang mendapat tugas itu, terjadilah perselisihan yang mendorong terjadinya pemogokan umum di kantor-kantor pegadaian. Revolutionaire Vakcentrale (Persatuan Serikat Buruh Revolusioner) Semarang ikut berperan dalam menyebarluaskan anjurannya bagi seluruh kaum buruh di Hindia agar memberikan dukungan bagi kaum pemogok, baik berupa uang maupun lainnya (Sinar Hindia, 24 Januari 1922). Dalam surat kabar Sinar Hindia diberitakan bahwa 
pemogokan terjadi di 75 kantor pegadaian di Jawa, termasuk pegadaian Karangturi, Poncol, dan Depok di Semarang (Sinar Hindia, 21 Januari 1922).

Akan tetapi, pemogokan ini tidak berlangsung lama, karena pemerintah kolonial memberikan ancaman pemecatan bagi siapa saja yang melaksanakan pemogokan, dan dengan ancaman itu ternyata banyak kaum pemogok yang menjadi onderkruiper (orang yang masuk secara diam-diam) (Sinar Hindia, 24 Januari 1922). Keamanan onderkruiper itu terjamin, karena pemerintah segera menugaskan polisi bersenjata untuk menjaga semua kantor pegadaian, dan melindungi orang-orang yang bersedia bekerja kembali.

\section{Pemogokan Buruh Kereta Api: Melawan Ketidakadilan Sosial}

Setelah kegagalan pemogokan buruh pegadaian di kantor Pegadaian Ngupasan di Jogjakarta pada Januari 1922, kekuatan dalam pergerakan buruh di Semarang melemah. Tan Malaka dan P. Bergsma ditangkap dan diasingkan, karena dituduh telah memimpin pemogokan di Pegadaian Ngupasan, dan Semaoen, yang pada periode itu menjadi pimpinan Serikat Buruh Kereta Api (Vereniging van Spoor en Tramweg Personeel/VSTP), telah pergi ke Rusia pada Oktober 1921 untuk menghadiri kongres buruh Timur Jauh di Moskouw yang dimulai pada 11 November 1921. Dalam kongres tersebut dibahas persoalan-persoalan organisasi buruh komunis internasional di daerah-daerah jajahan (J. Th. Petrus Blumberger, 1987: 141).

Pada tanggal 24 Mei 1922 Semaoen pulang ke Semarang, dan ketika itu ia telah menghadapi kenyataan bahwa pergerakan buruh di kota itu telah melemah. Ia merasa perlu untuk menghidupkan kembali pergerakan buruh revolusioner. Ia berpendapat bahwa serikat-serikat buruh harus dipersatukan kembali dalam suatu organisasi yang baru.

Pada tanggal 25 Juni 1922 Semaoen menyelenggarakan rapat untuk serikat-serikat buruh, terutama serikat buruh yang berafiliasi pada Partai Komunis Hindia (PKI). Dalam rapat tersebut dibicarakan terutama mengenai perlunya diadakan fusi antara Persatuan Perkumpulan Kaum Buruh (PPKB /Vakcentrale) dan Revolutionaire Vakcentrale (Persatuan Serikat Buruh Revolusioner). Rencana penyatuan kembali kedua organisasi itu dapat terlaksana pada tanggal 3 September 1922 dalam suatu rapat di Madiun. Tujuan pelaksanaan fusi adalah untuk menggalang persatuan guna melawan kapitalisme. Federasi serikat yang baru ini diberi nama "Persatoean Vakbonden Hindia" (PVH = Persatuan Serikat Buruh di Hindia). Beberapa serikat buruh yang tergabung dalam PVH adalah Persatoean Pegawai Pegadean Boemipotera (PPPB), Persatuan Goeroe Hindia Belanda (PGHB), Persatoean Goeroe Bantoe, VSTP (Vereeniging van Spoor en Tramweg Personeel = Persatuan Buruh Kereta Api dan Tram), Personeel Fabriek Bond (PFB = Persatuan Buruh Pabrik). Jumlah anggota PVH mencapai 20.000 orang ((J. Th. Petrus Blumberger, 1987: 141-142).

Krisis dunia yang memuncak sejak pertengahan 1922 semakin menghimpit kehidupan kaum buruh. Berbagai perusahaan melaksanakan penghematan dengan menghapuskan tunjangan kemahalan, dan masih disusul dengan tindakan-tindakan penghematan yang lain yaitu: menganjurkan para pegawai 
agar mengundurkan diri dengan pesangon; mulai Januari 1923 tunjangan tahunan diturunkan 50\%; menaikkan harga sewa perumahan pegawai dari $10 \%$ gaji menjadi $15 \%$ gaji; menghapuskan tunjangan perumahan; menurunkan gaji permulaan dan tunjangan jabatan; pakaian dinas hanya diberikan sekali, selanjutnya pegawai harus mengeluarkan biaya sendiri; penghapusan segala tambahan gaji; penurunan jumlah uang lembur (John Ingleson, 1986: 228-229).

Dalam menanggapi pengaturan-pengaturan yang semakin menyulitkan perekonomian kaum buruh itu, pada hari Natal tahun 1922, Persatoen Vakbonden Hindia mengadakan rapat di Semarang. Dalam rapat ini Semaoen melihat kaum buruh sudah sedemikian resah. Oleh karena itu pada Januari 1923 Semaoen, selaku pimpinan VSTP, membuat surat edaran yang berisi usulan bagi kaum buruh kereta api untuk melaksanakan pemogokan, jika tunjangan kemahalan dihapus. Usulan ini dibicarakan lagi dalam rapat VSTP pada awal Februari 1923. Dalam rapat itu VSTP juga memperingatkan direksi perusahaan kereta api dan tram, agar "jangan main api”.

Pada tanggal 12 April 1923 Semaoen menemui pimpinan Staatsspoor untuk membicarakan halhal sebagai berikut: (1). tetap memberikan tunjangan kemahalan bagi para buruh, (2). jumlah jam kerja 8 jam per hari, (3). pembentukan dewan pendamai (verzoeningsraad), (4). memberikan upah minimum f. 1,per hari (Surat Edaran VSTP, SANGET PENTING 23 April 1923).

Pembicaraan antara Semaoen dan pimpinan Staatsspoor (Perusahaan Kereta Api Negara) tidak membuahkan hasil seperti yang diharapkan oleh kaum buruh. Semua tuntutan tidak dapat dipenuhi oleh perusahaan (Sinar Hindia, 5 Mei 1923). Kegagalan dalam perundingan dengan pimpinan perusahaan itu menjadi agenda utama pada rapat VSTP yang diselenggarakan pada hari Selasa, 30 April 1923 yang dipimpin oleh Kadarisman. Menurut Kadarisman, alasan untuk menolak usulan mereka sangatlah tidak masuk akal dan menggelikan. Pihak perusahaan mengatakan bahwa belum ada pegawai yang kekurangan makan hingga mati, bahkan para pegawai tampak gemuk-gemuk dan sehat-sehat. Jawaban yang menggelikan dan mengecewakan ini mendorong mereka untuk bergerak secara bersama-sama. Jika masih ada yang mau bekerja, itu berarti makan darah saudara sendiri ("Rapport-Rahasia", Laporan Mantri Politie Gew. Recherche, 1 Mei 1923).

Akhirnya Semaoen memutuskan untuk menyerukan aksi mogok bagi seluruh pegawai kereta api di Semarang. Pada tanggal 29-30 April 1923 PVH menyelenggarakan rapat di Surabaya. Dalam rapat tersebut pengurus VSTP (Semaoen, Kadarisman, Soegono, dan Soedibjo) mengumumkan manifest (pernyataan umum) bahwa jika pemogokan terjadi, Semaoen akan diangkat sebagai diktator VSTP, dan pemogokan umum harus dilancarkan segera setelah Semaoen ditangkap. Selanjutnya, Semaoen menyatakan bahwa ia tidak merasa takut dengan ancaman bui dan pembuangan dari pemerintah demi memperjuangkan kepentingan pegawai spoor dan tram (Surat Gubernur Jenderal Fock kepada Menteri Daerah Jajahan De Graaff, 16 Mei 1923 dalam Verbal. 14 Juli 1923 No. 15).

Karena pernyataan Semaoen di depan umum ini, pada tanggal 8 Mei 1923 Semaoen yang pada saat itu menumpang di kantor Partai Komunis Hindia di Tegal Wareng, ditangkap dan ditahan di penjara 
di alun-alun Semarang dengan tuduhan spreek-delict (pelanggaran terhadap peraturan membuat pernyataan secara lisan di depan umum). Ia tidak mempunyai kesempatan untuk berbicara tentang penangkapan itu dengan istrinya yang ketika itu sedang melahirkan.

Pada hari itu juga, kaum buruh kereta api di Semarang menyelenggarakan rapat di gedung Sarekat Islam di kampung Gendong untuk memproklamasikan bahwa sejak saat itu pemogokan harus dimulai. Ajakan mogok juga disiarkan melalui harian milik Sarekat Islam Semarang, Sinar Hindia, 8 Mei 1923.

Pada tanggal 9 Mei 1923, pecahlah pemogokan umum di kota Semarang. Pemogokan tidak hanya dilakukan oleh pegawai kereta api, tetapi juga oleh berbagai pekerja di kota ini: tram kota Jomblang-Bulu, bengkel kereta api Semarang-Juana, pegawai-pegawai bumiputera, pedagang-pedagang di pasar Johar dan Pedamaran, dan tukang-tukang sado. Suasana kota menjadi sangat sepi dan mobilitas macet. Para "jongos" dan "babu" yang biasa mengirim makanan untuk majikan mereka di kantor-kantor terpaksa harus berjalan kaki. Kereta api Nederlanadsch Indische Spoorweg Maatschappij (NIS), Semarang Joewana Spoor (SJS), dan Semarang Cirebon Spoor (SCS) tidak dapat beroperasi, karena masinis, stoker (petugas menyalakan api), kondektur dan pegawai-pegawai bumiputera yang lain ikut mogok. Untuk melancarkan kembali perhubungan dalam kota, tram kota dijalankan oleh tenaga bantuan dari siswa-siswa bangsa Belanda Technische School (Sekolah Teknik) di Semarang. Setiap gerbong tram kota itu dijaga oleh polisi. Demikian juga stasiun-stasiun NIS, SJS, dan SCS dijaga oleh polisi bersenjata. Pemogokan buruh kereta api ini mengundang solidaritas para pekerja di sektor-sektor yang lain. Pada keesokan harinya, tanggal 10 Mei 1923, menyusul aksi pemogokan pedagang-pedagang di Kota Semarang, antara lain para pedagang di pasar Dargo, Peterongan, Karangbidara, dan kusir-kusir dokar (Liem thian Joe, 1931: 260-261).

Seruan pemogokan buruh kereta api itu ternyata tidak hanya mendapat sambutan di Semarang, tetapi juga menggerakkan solidaritas kaum buruh kereta api di berbagai tempat. Para buruh kereta api di stasiun Weleri, Pekalongan, Tegal, Cirebon, Kertosono, Madiun, dan Surabaya juga ikut mogok (Liem Thian Joe, 1931: 260-261).

Konsolidasi untuk memperkuat pertahanan pemogokan terus dilakukan. Pada tanggal 10 Mei 1923 diadakan rapat lagi yang dipimpin oleh Soemantri. Rapat tersebut dihadiri wakil-wakil VSTP, PKI, PVH, Pasarbond (Persatuan Buruh Pasar), Kleermakerbond (Persatuan Tukang Jahit), Nationaal Indische Partij (NIP), Gemeentebond (Persatuan Pegawai Gemeente/Kota Praja), dan Dokarbond (Persatuan Kusir Dokar). Dalam rapat itu Darsono memberi anjuran-anjuran dan menguatkan semangat kaum pemogok.

Karena pemogokan buruh kereta api yang berpusat di Semarang ini telah mengakibatkan pemogokan di berbagai sektor ekonomi, pemerintah kolonial tidak tinggal diam. Pemerintah segera melakukan campur tangan untuk menindas gerakan buruh itu. Pemberlakuan pasal 161 bis membuat kaum pemogok tidak berdaya lagi. Para pemimpin pemogokan buruh ditangkap dan diasingkan. Harapan untuk mencapai kemenangan pemogokan setelah menjalankan puasa Ramadhan telah sirna sebelum hari 
raya tiba. Pemogokan pun berakhir pada akhir Mei 1924 (J. Th. Petrus Blumberger, 1987: 144.). Akhirnya, pengurus pusat VSTP harus mengumumkan kekalahan mereka kepada seluruh cabang VSTP (John Ingleson, 19816: 250).

\section{Simpulan}

Dari pembahasan di atas dapat dipetik simpulan bahwa kegagalan tuntutan buruh untuk perbaikan nasib sering disebabkan oleh cara-cara pengusaha untuk melumpuhkan daya tahan buruh dalam melaksanakan pemogokan dengan memanfaatkan strike breaker (tenaga pengganti kaum pemogok). Dengan demikian, selama pemogokan perusahaan tetap dapat beroperasi, sedangkan kaum pemogok, karena lemahnya kekuatan ekonomis dan organisasi mereka, terpaksa menerima kekalahan dengan bekerja kembali pada kondisi kerja yang lama.

Campur tangan negara yang sering berpihak kepada pengusaha membuat kaum pemogok tidak berdaya, karena keberpihakan itu dilembagakan secara hukum dan dapat digunakan untuk menghukum siapa saja yang dianggap melanggarnya.

Perkembangan kapitalisme yang eksploitatif telah melahirkan kelas-kelas sosial yaitu kelas yang menguasai modal atau alat-alat produksi atau the have, dan kelas buruh yang sebagian besar adalah orang bumiputera yang miskin atau the have not. Pengalaman bersama kaum buruh bumiputera di bawah sistem kapitalisme yang eksploitatif yang tercermin pada rendahnya tingkat upah dan kesejahteraan, rendahnya posisi pekerjaan, dan perlakuan tidak adil dalam hubungan industrial merupakan basis kemunculan kesadaran kelas buruh akan nasib dan kedudukannya dalam lingkup masyarakat industrial dan kolonial.

Nasionalisme antikolonial juga menjadi kekuatan penting yang mendorong kaum buruh untuk memperjuangkan perbaikan kondisi kerja dan kesejahteraan dalam lingkup masyarakat industrial dan kolonial. Jika John Ingleson memandang bahwa golongan intelektual di kota-kota menjadi pelopor pergerakan nasional, dan Takashi Shiraishi menempatkan para pemimpin organisasi atau partai seperti Tjokroaminoto, Soerjopranoto, H. Agoes Salim sebagai pahlawan nasionalis, penelitian ini menunjukkan fenomena bahwa massa buruh pun menjadi pelopor nasionalisme. Ketika terjadi pemogokan, solidaritas mereka sangat tinggi. Gejala tersebut dapat diketahui dari: 1) kondisi bahwa majikan-majikan Eropa mengalami kesulitan untuk mencari pengganti pemogok bumiputera; 2) slogan "jika masih ada yang mau bekerja, itu berarti makan darah sendiri; 3) solidaritas dalam rapat-rapat umum, yang tidak hanya dihadiri oleh buruh-buruh terkait dengan perusahaan, tetapi juga oleh buruh-buruh lainnya dan organisasiorganisasi buruh, antara lain pedagang, tukang sado, "jongos dan babu”, kleermakerbon (Persatuan Penjahit), Gemeentebond (Persatuan Pegawai Gemeente), Dokarbond (Perstuan Kusir Dokar), dan Nationaal Indische Partij.

Nasionalisme buruh bumiputera sangat tampak ketika ada rapat-rapat umum. Meskipun sering kali mereka harus berdesakan karena keterbatasan tempat, mereka menghadiri rapat-rapat umum itu dengan penuh antusias untuk menemukan jalan guna memperjuangkan perbaikan nasib orang bumiputera. 
Walaupun ketika itu pengertian nasionalisme masih hanya dipahami oleh sekelompok kecil intelektual, gejalanya sudah dapat disaksikan di kalangan kaum buruh, kaum "kromo" ("kromo" digunakan untuk menyebut rakyat jelata bumiputera yang miskin [proletar]), dan hanya mempunyai tenaga untuk dijual pada kapitalis baik swasta maupun pemerintah.

\section{Daftar Pustaka}

Anderson, Benedict, R. O'Gorman, 1983, Imagined Communities Reflections on The Origin and Spread of Nationalism, Thetford, Norfolk: Thetford Press Limited

Ari Dwipayana, AAGN., 2001, Kelas dan Kasta Pergulatan Kelas Menengah di Bali, Yogyakarta: Yayasan Adikarya IKAPI dan The Ford Foundation.

Baars, A. "Het eerste resultaat. Ontwerp Beginselverklaring", dalam Het Vrije Woord, No. 2, 20-101917.

Blumberger, J. Th. Petrus, 1987, De Nationalistische Beweging in Nederlandsch - Indië, Dordrecht Holland / Providence-U.S.A.: Foris Publications.

Breman, Jan, 1987, Koelies, Planters en Koloniale Politiek, Foris Publications: DordrechtHolland/Providence-U.S.A.

Brewer, Anthony, 1999, Kajian Kritis Das Kapital Karl Marx, Jakarta: Teplok Press.

Brommer, B., A. Sidharta, E. Budihardjo, A. Siswanto, A.B. Montens, Soewarno, S. Setiadi, Th. Stevens, 1995, Semarang Beeld van Een Stad, Purmerend: Asia Maior.

Budiman, Amen, "Oei Tiong Ham”, dalam Suara Merdeka, 23-7-1976.

Ensiklopedi Indonesia, 1980, Jakarta: Ikhtiar Baru-Van Hoeve.

Ingleson, John, 1986, In Search of Justice Workers and Unions in Colonial Java, 1908-1926, Singapore, Oxford, New York: Oxford University Press. 2000.

Kartonegoro, Sentanoe, 1999, Hubungan Industrial Hubungan Antara Pengusaha dan Pekerja (Bipartit) dan Pemerintah (Tripartit), Jakarta: Yayasan Tenaga Kerja Indonesia.

Kwantes, R.C. (ed.), 1978, De Ontwikkeling van De Nationalistische Beweging in Nederlandsch-Indië, Bronnen Publikatie, Eerste Stuk: 1917-medio 1923. Groningen: Tjeenk Willink and Wolters Noordhoff.

Larson, George D., 1987, Prelude to Revolution Palaces and Politics in Surakarta 1912-1942,DordrechtHolland/ProvidenceU.S.A.: Foris Publications.

Liem Thian Joe, 1931, Riwayat Semarang 1416-1931 (Dari Djamannja Sam Poo Sampe Terhapoesnja Kong Koan), Semarang.

Malaka, Tan, 1991, Madilog Materialisme, Dialektika,Logika, Jakarta: Pusat Data Indikator,. 2000, Aksi Massa . Jakarta: Teplok Press.

Poeze, Harry A., 1976, Tan Malaka Strijder voor Indonesische Vrijheid Levensloop van 1897 Tot 1945, 's-Gravenhage: Martinus Nijhoff. 